\title{
Terapia combinada con electroestimulación y apósitos convencionales, como tratamiento de úlceras y heridas en pacientes en hemodiálisis
}

\author{
Esperanza Melero Rubio - Mateo Párraga Díaz
}

Enfermeros

Hospital Universitario Virgen de la Arrixaca, El Palmar (Murcia).

\section{Introducción}

Las intervenciones que enfermería realiza a los pacientes para la prevención y tratamiento de heridas y úlceras durante las sesiones de hemodiálisis cada vez son más numerosas. Para su realización existen numerosos productos ${ }^{1}$ : hidrogeles, apósitos (con alginato cálcico, con plata, zinc, magnesio, con carbón activado, hidropoliméricos, adhesivos y no adhesivos, trasparentes o no) y técnicas alternativas, como la electroestimulación para acelerar la reparación de tejidos.

Puede ser difícil la elección del protocolo a seguir para la cura de una herida; aunque existen numerosas guías que pueden ayudar a discriminar el estado de la herida y a elegir un determinado producto más adecuado. Es la evolución del estado de la piel y la evaluación de la herida lo que debe determinar la efectividad del protocolo de cura elegido.

En el caso que se presenta el protocolo de actuación fue la aplicación de un apósito de carbón activado $y$, como novedad, se introdujo el uso combinado de un tratamiento de electroestimulación. La aplicación de un apósito de carbón activado pretende en

Correspondencia:

Esperanza Melero Rubio

Unidad Diálisis. HUVA

Ctra. Madrid-Cartagena, s/n

30120 El Palmar (Murcia)

emeleror@terra.es primer lugar el desbridamiento y la reducción de la carga bacteriana (con lo que se inhibe la infección y se elimina el mal olor) ${ }^{2}$. La frecuencia del cambio de apósito (recomendado cada tres días ${ }^{2}$ ) fue adaptada a la asistencia al programa de hemodiálisis. Las terapias de electroestimulación presentan como mecanismo de acción ${ }^{3}$ la reactivación funcional de los tejidos biológicos degenerados debido a la descompensación metabólica, a la desactivación de procesos de feedback neuromuscular sintomáticos, a la movilización de factores inflamatorios y pro-inflamatorios y a la aceleración de la reparación del tejido dañado. Estos mecanismos hacen que las aplicaciones de la electroestimulación, en diversas especialidades incluida la nefrología, sean numerosas: patologías ortopédicas, neurológicas y patologías vasculares (patologías de la microcirculación, microangiopatía periférica, vasculopatía diabética, estasis venoso, úlceras, heridas por presión) ${ }^{3}$.

\section{Objetivo}

1. Recuperar la integridad de la piel del paciente en el menor tiempo posible.

2. Presentar los resultados obtenidos al aplicar de forma combinada en el tratamiento de una herida apósito y terapia electroestimuladora (o sistema FREMS).

\section{Resumen historia clínica}

Varón de 50 años, diagnosticado de diabetes tipo 1 a los 13 años sin control hasta los 35 años y que en la actualidad presenta malnutrición calórica-proteica. Nefropatía diabética con insuficiencia renal crónica 
en tratamiento sustitutivo renal desde diciembre de 2003, portador de catéter tunelizado tras varios accesos autólogos fracasados. Angiopatía con amputación de tercio distal pie derecho y primer metatarsiano pie izquierdo. Repetidos ingresos para tratamiento de ulceras en ambas extremidades.

En julio de 2007 ingresa para amputación de Syme en pie izquierdo por escara necrótica en talón y varias lesiones más en antepie. Hasta el momento del ingreso la cura de la herida se realizaba en la sala de hemodiálisis y según protocolo de Consulta Pie Diabético (lavado suero fisiológico y povidona yodada). Tras la intervención quirúrgica se observa una dehiscencia de sutura, aunque con posterioridad la cicatrización evoluciona favorablemente y es dado de alta a su domicilio para revisión ambulatoria. Desde el alta se cura la herida quirúrgica durante la sesión de diálisis: limpieza con suero fisiológico e impregnación con povidona yodada. Trascurridas varias semanas, se constata la mala evolución, produciéndose agrandamiento de la herida con escaso tejido de granulación, esfacelos y mal olor (Grado II). La piel circundante presenta buen estado (no macerada, ligeramente eccematosa aplicando crema hidratante).

Valorada la herida de nuevo y conocida la historia del paciente en relación a la evolución tórpida de cualquier herida se decide junto con la Consulta del Pie Diabético un cambio en la estrategia a seguir: limpieza de herida con suero fisiológico, poner apósito de carbón activado con plata y cubrir con gasas y una venda. Cada día que el paciente asistiera a hemodiálisis se aplicaría una sesión con electroestimulador de treinta minutos hasta recibir un total de 15 sesiones.

\section{Evolución}

Si analizamos el resultado obtenido según las diferentes etapas de la herida (figuras 1-5), lo primero que podemos resaltar fue la rápida eliminación del olor al aplicar el apósito de carbón activado. La mejoría en el aspecto de la herida tras dos semanas de inicio del protocolo de cura nos sirvió para confirmar que nuestra valoración había sido la adecuada y que la opción elegida entre las diferentes opciones ${ }^{1}$ la acertada.

La favorable evolución en las siguientes semanas hasta la total curación en la séptima semana demostró que el tratamiento con el apósito fue efectivo y que la aplicación conjunta con el electroestimulador había propiciado y acelerado ${ }^{3}$ dicha curación. El protocolo de actuación no se cambió en ningún momento y durante el tiempo de aplicación del tratamiento no aparecieron en la herida signos de infección y el paciente no superó en ninguna sesión el umbral de dolor.

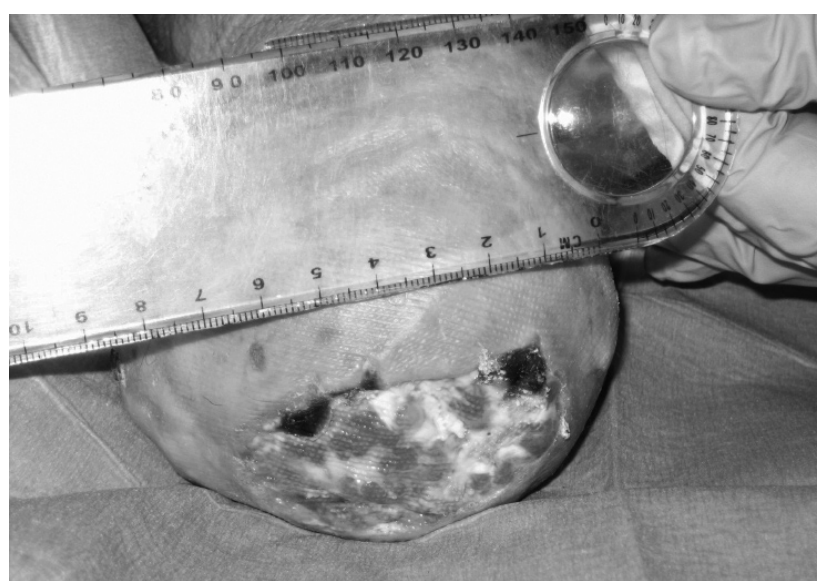

Figura 1: Inicio tratamiento

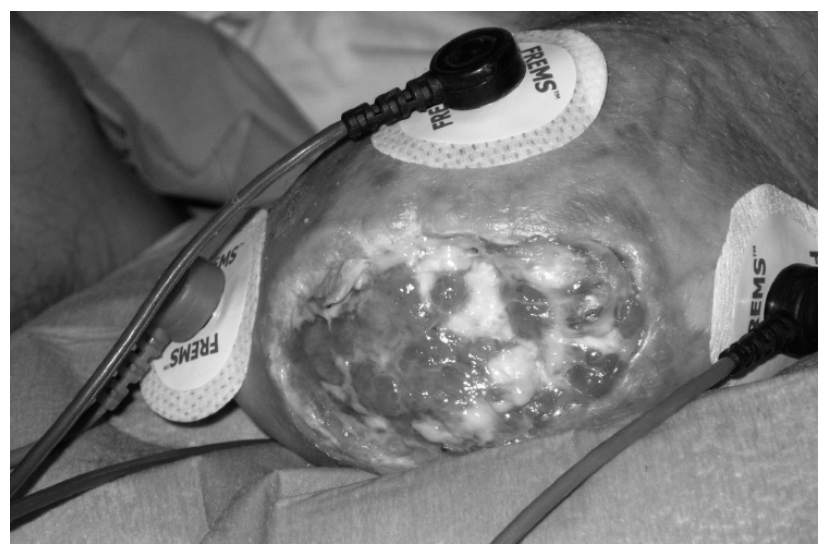

Figura 2: $2^{\text {a }}$ Semana

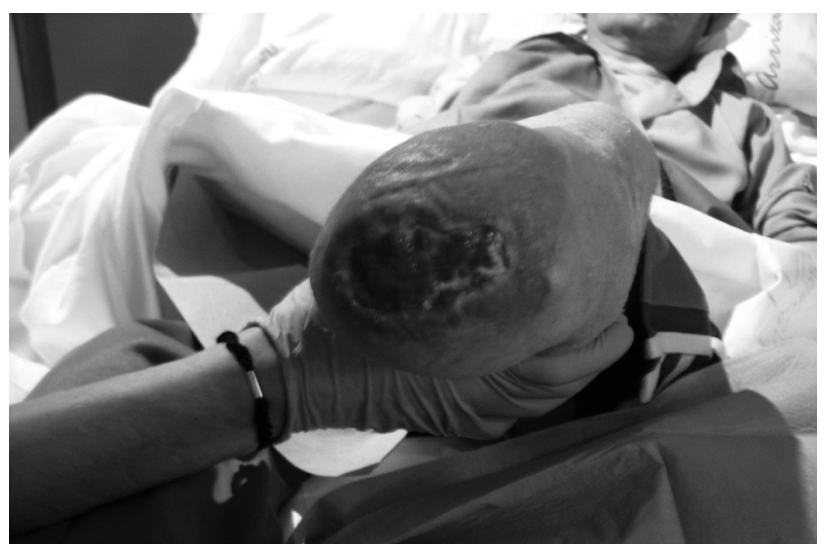

Figura 3: $4^{\mathrm{a}}$ Semana 


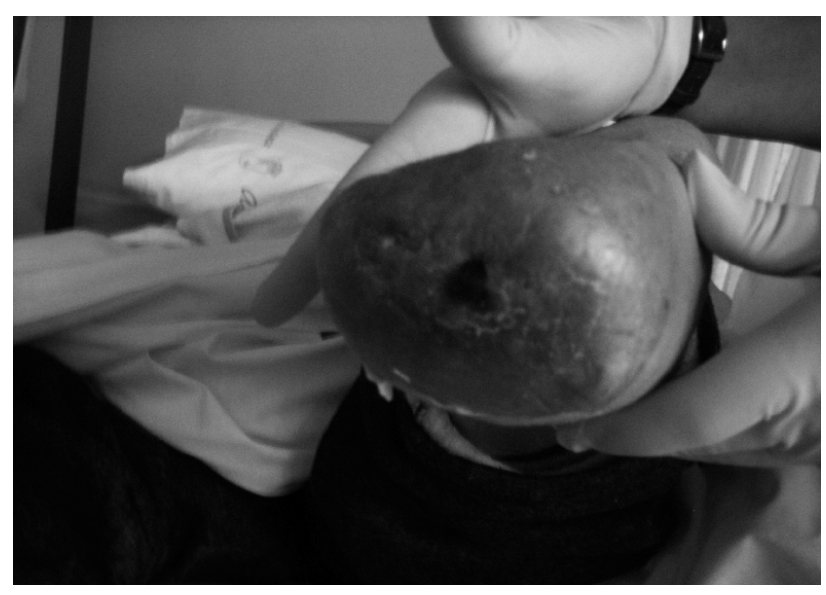

Figura 4: $7^{\text {a }}$ Semana

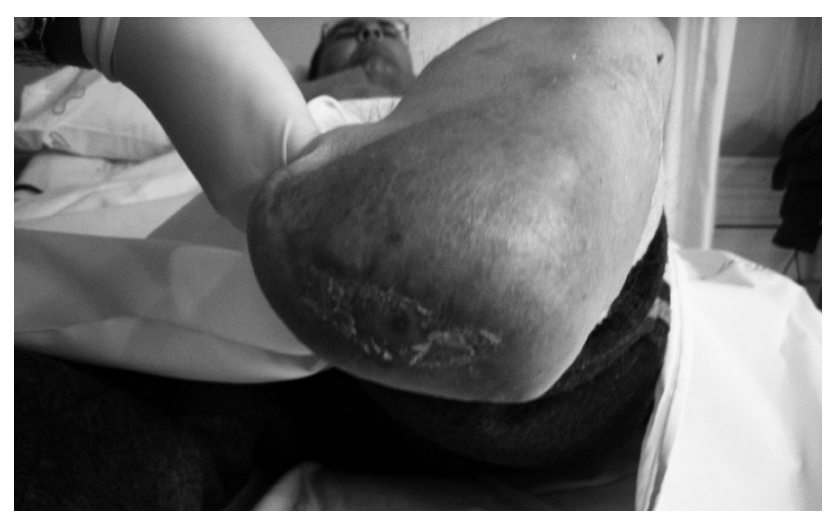

Figura 5: Fin de tratamiento
Tras dos meses de tratamiento de terapia combinada se logró la recuperación total de la integridad cutánea a nivel talón del pie izquierdo sin molestias para el paciente derivadas del tratamiento realizado, por lo que concluimos que el protocolo utilizado es eficaz para el tratamiento de heridas de evolución tórpida en pacientes nefrológicos.

\section{Bibliografía}

1. Mateos Rodilla J, Martínez Piédrola M, Lebrancón Cortés PR, Salobral de la Rubia I, Arnaiz Alonso R, Ramírez Sanz M y cols. Ficha terapéutica en el cuidado de lesiones dérmicas. Rev de Enf Rol. 2007; 30:42-43.

2. Ficha técnica de Actisorb Plus $25^{\circledR}$.

3. Lorenz Biotech S.p.A. Manual del operador Aptiva. Julio 2004 